\title{
ACTUALIDAD DE ZUBIRI EN AMÉRICA LATINA
}

\author{
Germán Marquínez Argote \\ Fundación X. Zubiri, Madrid
}

\section{Resumen}

Zubiri ha venido cobrando creciente actualidad en Latinoamérica. Actualidad no significa estar de moda, sino estar presente. El trabajo da cuenta rigurosamente documentada de esa presencia, identificando hasta cuatro etapas y determinando los principales cauces tenidos en cada una de ellas. En la primera, de 1931 a 1936, el gran cauce fue la Revista de Occidente, de amplia resonancia entre la joven intelectualidad latinoamericana del momento. La segunda, iniciada en la posguerra española, su principal cauce fue el libro Naturaleza, Historia, Dios, además de la obra editorial y docente de los "trasterrados", como José Gaos y María Zambrano, entre otros. La tercera, inaugurada en 1962, año de publicación de Sobre la esencia, de positiva recepción por pensadores como el mexicano Agustín Basabe, el chileno Jorge Ribera, Ignacio Ellacuría en El Salvador y el propio Germán Marquínez en Colombia. Finalmente, la cuarta, arranca con la publicación de la Trilogía sobre la inteligencia, 1980-1983, en la cual se vienen destacando tres grupos de investigación zubiriana establecidos en El Salvador, Colombia y Chile, respectivamente.

\section{Palabras clave}

Xavier Zubiri, América Latina, actualidad, “Naturaleza, Historia, Dios”, "Sobre la esencia”.

\section{Abstract}

Mr. Zubiri has been gaining a lot of updating in Latin America. Updating means not to be fashionable but to be present. The work accounts for such presence, by identifying four steps and determining the main ways taken into account in each one of them. In the first one step (1931 - 1936), the main guide was Revista de Occidente, largely known 
among the current Latin American intellectual youth. The second one, starting in the Spanish post war; its main guide was the book called Naturaleza, Historia, Dios, as well as the work of those banished people such as Jose Gaos and María Zambrano. The third one - inaugurated in 1962 - a very important year for those thinkers such as Mexican Agustin Basade and Chilean Jorge Rivera, as well as Ignacio Ellacuría from El Salvador and Germán Marquinez From Colombia. And the last one, starts with the trilogy publication about intelligence (1980 - 1983); in such step three Zubirian research groups are highlighted which established in El Salvador, Colombia and Chile.

\section{Index terms}

Xavier Zubiri, Latin America, actuality, “Naturaleza, Historia, Dios”, “Sobre la esencia”.

Empecemos diciendo que la filosofía de Zubiri nunca estuvo de moda en América Latina, pero que siempre ha estado de "actualidad", si por tal se entiende lo que este término zubirianamente significa: "estar presente”. Esta actualidad o presencia atravesó por diversas etapas de acuerdo con las cambiantes circuntancias y al compás un tanto irregular de las publicaciones de Zubiri. Es lo que voy a exponer a continuación.

\section{Primera etapa}

La primera etapa es la comprendida entre 1931-1936. En este corto lapso de tiempo, anterior a la guerra civil española, la Facultad de Filosofía y Letras de la Universidad de Madrid alcanzó gran prestigio interior y proyección internacional. En ella José Ortega y Gasset era reconocido como maestro común, Manuel García Morente fungía de decano, mientras que Xavier Zubiri y José Gaos representaban dos jóvenes promesas. El medio principal de expresión de este admirable grupo, llamado posteriormente "Escuela de Madrid”, fue Revista de Occidente, fundada por Ortega en 1923. La generación americana emergente en estos ya lejanos años esperaba con avidez la llegada a las librerías de la revista de Ortega: "Para América Latina la Revista de Occidente significó un ponerse a la altura de los tiempos. De pronto se encontraba a su inmediato alcance lo mejor de la creación cultural europea y en español” . En ella publicó Zubiri algunos de sus más originales y sugestivos ensayos: "Sobre el problema de la filosofía” y "En torno al problema de Dios”. Además, en la editorial homónima de la revista dio a conocer Zubiri en traducciones fiables textos fundamentales de Suárez, Descartes, Pascal, Hegel, Brentano, Scheler, Messer, March, Schrödinger y De Broglie. Aunque en menor grado, parecida aceptación alcanzó en América la revista Cruz y Raya, fundada por José Bergamín y dirigida Eugenio Imaz. En ella, desde el primer número aparecido en 1933, tuvo Zubiri una destacada presencia con ensayos tan memorables como: "Hegel y el problema metafísico”, "La nueva física”, "Filosofía y metafísica”, etc. También en Cruz y Raya apareció en 1933 “¿Qué es metafísica?”, lección magistral dada por Heidegger en la toma de posesión de su cátedra en la

1 MODIN, Izvi. Ortega y Gasset y la cultura hispanoamericana. México: FCE, 1994, p. 33. 
Universidad de Friburgo en 1929, acto al que asistió Zubiri. Esta ejemplar traducción tuvo no menos de cinco reediciones en varios países de América Latina².

\section{Segunda etapa}

La segunda etapa se extiende desde los primeros años de la posguerra española hasta la aparición del controvertido tratado Sobre la esencia a finales de 1962. Son veinte largos años de escasas publicaciones en los que la presencia de Zubiri se hizo sentir en América Latina por otros cauces. El primer cauce fue el grupo de los “transterrados”, que junto con la nostalgia de su patria de origen, llevaron a sus nuevas patrias de destino la memoria de la experiencia filosófica compartida con los amigos en España dejados ${ }^{3}$. Ejemplar, el caso de José Gaos. Apenas arribado a México, publicaba un revelador ensayo sobre "La filosofía en España”, destacando el extraordinario momento de creación filosófica vivido en Madrid bajo el magisterio de Ortega y al lado de Zubiri, a quien califica de "hermano mayor y magistral en filosofía”4. Entre otras cosas, escribe de Zubiri que "es la personalidad intelectual más relevante de las últimas generaciones españolas"; que "sus saberes son insólitos en una sola persona”; que "su inteligencia es un aparato mental de una sutileza, pero también de una capacidad de asociaciones sorprenden- tes, que ha admirado siempre a sus auditores"; y, finalmente, que "su obra impresa y publicada es todavía poco extensa, pero cualquiera aprecia en ella su densidad y personalidad germinal”. Nunca olvidaría Gaos que fue Zubiri, antes de irse para Alemania, el ponente de su tesis doctoral sobre Husserl ${ }^{6}$ y que, a su regreso, estudió “en consulta constante con Zubiri, a lo largo de un año El ser y el tiempo"7 de Heidegger, de donde saldría la traducción gaosiana, publicada en México en 1951. En sus famosas Confesiones profesionales de 1958 señalaba Gaos las dos raíces del pensamiento zubiriano: antes de su ida a Alemania, “para Zubiri, parecía no haber más que la fenomenología”; pero, a su regreso, “Zubiri venía entusiasmado, no sólo de Heidegger, sino con Heidegger”, de manera que "mi Zubiri de la fenomenología me lo encontraba hecho un Zubiri del existencialismo"; para concluir diciendo que "a defecto de Heidegger mismo, era Zubiri el mejor maestro concebible"».

Desde sus sucesivos destinos (México, Cuba, Puerto Rico), María Zambrano evocaba a su vez nostálgicamente “el logos del Manzanares”, en referencia a sus dos maestros Ortega y Zubiri, y la ciudad de Madrid, “lugar éste que ha sido para mí decisivo y pe-

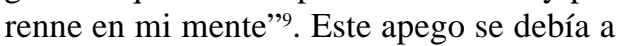
que “durante años y más años asistí a sus clases y seminarios [de Zubiri], como a las de Ortega, y hasta le sustituí [a Zubiri] durante

\footnotetext{
2 México, Ed. Séneca, 1941; Buenos Aires, Ed. Alpe, 1955; Santiago de Chile, Cruz del Sur, 1963; Buenos Aires, Siglo XX, 1967; Bogotá, El Búho, 1992, ésta última con amplios comentarios de Jaime Hoyos Vázquez, gran admirador de Zubiri.

ABELLÁN, José Luis. Filosofía española en América, 1936-1966. Madrid, 1967.

4 GAOS, José. “Nota personal (1939-1940)”. En: Obras completas, vol. XIX, p. 437.

5 GAOS, José. “La filosofía en España”. En: Letras de México, 15 de enero de 1939; también en: Obras completas, vol. IV, pp. 235-242.

GAOS, José. “Crítica al psicologismo en Husser”. Tesis leída el 30 de enero de 1929.

GAOS, José. Obras completas, vol. VII, p. 231; y vol. X., p. 18.

GAOS, José. Obras completas, vol. XVII, pp. 61-64.

ZAMBRANO, María. De la aurora. Madrid: Ed. Turner, 1986, p. 122.
} 
un curso entero mientras estuvo en Alemania junto a Heidegger" ${ }^{10}$. De estos años nos dejó un magnífico retrato de Zubiri como persona física, pensador y maestro: “Con un metro cincuenta se puede ser alto y lo era Zubiri cuando lo conocí... Era esbelto, elegantísimo. Un raro lirio oscuro, negro, claro, de negro iba y qué bien le estaba. Tenía el sentido del ser en grado sumo — del SER; profundizaba, exponía sin concesión pedagógica alguna”"11. Pero el hecho más decisivo fue el curso que Zubiri impartió recién vuelto de Alemania, entre 1931-1932, “que tuve la fortuna de escuchar"12. En ese momento estaba la malagueña a punto de abandonar los estudios de filosofía, pero "un día inolvidable, el mes de mayo había de ser, por una de las rendijas del edificio de San Bernardo que daba a un patio, entró un rayo de claridad: el profesor Zubiri explicó nada menos que las Categorías de Aristóteles y yo me encontré no dentro de una revelación fulgurante, sino dentro de lo que siempre ha sido mejor para mi pensamiento: la penumbra tocada de alegría. Y, entonces, calladamente se fue abriendo como una flor el discernido sentir de que quizá yo no tenía por qué dejar de estudiar filosofía”13.

Abundando en más ejemplos, está Ramón Gómez de la Serna, amigo de los filósofos de su generación y cuyas greguerías son gotas destiladas de ingenio y de filosofía quintaesenciada en muchos casos. Pues bien, desde Santiago de Chile escribía en 1958 la siguiente nota: “Querido Zubiri: el más viejo amigo (dicen que amigos nuevos no los hay) que me queda en Madrid eres tú. ¡Nunca he dejado de recordarte en el transcurso de estos largos años! Quiero enviarte hoy un abrazo con este ligero recorte. Ramón de la Serna”"14. El recorte adjunto era un evocador artículo, “En un camino de Hendaya”, que así se titulaba, publicado en el periódico El Mercurio de la capital chilena. En él relataba don Ramón su primer encuentro con Unamuno y con Zubiri allá por los años veinte. Zubiri lo recibió en su casa de San Sebastián, amplia, cómoda y bien abastecida de libros, quedando impresionado del joven anfitrión: "Yo consideraba ya a aquel muchacho, en lo suyo, como 'un monstruo de la naturaleza' a la manera de Lope, pero sólo en el verbo, en la palabra hablada, ya que una cautela muy de filósofo echaba frenos a su producción escrita, aún en génesis hoy, en laboreo y sin premuras de alumbramiento" ${ }^{15}$.

Se podrían multiplicar los testimonios de admiración y afecto a Zubiri de otros viejos amigos transterrados como Eugenio Imaz, Eduardo Nicol, Joaquín Xirau, Luis Recasens Siche, todos ellos exilados y reconocidos maestros en México; o de David García Bacca y Manuel Granell, quienes durante muchos años profesaron en la Universidad Central de Venezuela. Baste este último

10 ZAMBRANO, María. “Carta a Robles Bravo del 11-I-1977”. En: ORTEGA MUÑOZ., Juan. María Zambrano o la metafísica recuperada. Málaga: Ed. Universidad, 1982, p. 18.

11 ZAMBRANO, María. Cartas de la Pièce (correspondencia con Agustín Andreu). Valencia: Ed. Pre-textos, 2002, pp. 87 y 239.

12 ZAMBRANO, María. El hombre y lo divino. México: F.C.E., 1955, pp. 77 y 94-95.

13 ZAMBRANO, María. Hacia un saber sobre el alma. Madrid: Alianza Tres, 1983, p. 10; también en Delirio y destino. Madrid: Ed. Mondadori, 1989, p. 32. Ver: GÓMEZ CAMBRES., Gregorio. "El realismo de Zubiri y María Zambrano”. En: Varios autores. María Zambrano: raíces de la cultura española. Madrid: Fundación Rielo, 2004, pp. 81-117.

14 Don Ramón vivía habitualmente en Buenos Aires. La nota está fechada en "Santiago de Chile, junio de 1959. Av. Bustamante 176, Dpto. 1032”, donde vivía un hermano suyo.

15 DE LA SERNA, Ramón. "En un camino de Hendaya”. En: El Mercurio (Santiago de Chile) 7 de junio de 1958. 
textimonio. Cuenta Granell que un día le preguntó un estudiante que cómo era Ortega en su íntimo modo de ser y de pensar, a lo que respondió con la siguiente anécdota ocurrida en la primavera de 1933: "La Facultad madrileña de Filosofía y Letras disponía entonces de un cómodo autobús destinado a excursiones culturales. Un buen día, no sé cómo, me encontré dentro de aquel vehículo con Ortega y Xavier Zubiri. Siete u ocho compañeros de estudios filosóficos cercaban como moscas insistentes a los dos maestros. Íbamos rumbo a El Escorial”. Ya dentro del célebre monasterio, que tanto dio que meditar a Ortega, “estábamos en la nave central, amplia y altísima, exactamente bajo la luz cenital del cimborrio. Alzando el rostro, los dos pies bien plantados en las losas, su izquierda en la cintura y la diestra rubricando un solemne ademán que se alargaba como una espada, Ortega exclamó con brioso júbilo: ¡¡Qué maravilloso despacho!”. No había terminado de pronunciar tan rotunda frase admirativa, cuando Zubiri manifestó su desacuerdo: “¡Oh, no!... yo prefiero una habitación pequeña, muy pequeña, más empequeñecida aún por los libros que cubran las paredes. Me horroriza la idea de meditar en este espacio enorme, frío, abierto como un cruce de caminos”. Contado lo cual, Granell daba al estudiante caraqueño la respuesta requerida, contraponiendo el modo de ser de Zubiri con el de Ortega: "Desde entonces comprendí mejor los cerrados y sutiles análisis de Zubiri, siempre en inquieta visión cercana; y también las amplias visiones panorámicas, las altas cimas a que sabe llevarnos la mirada de azor de Ortega” ${ }^{16}$.
El segundo cauce de la actualidad o presencia de Zubiri en América fue Naturaleza, Historia, Dios, primer libro formal de Zubiri, que vio la luz pública en 1944, después de superar las engorrosas censuras propias de la época. Constituyó una corriente de aire fresco en el empobrecido mundo cultural de la posguerra española este libro, que reunía buena parte de lo anteriormente escrito por Zubiri, con algunos textos nuevos añadidos: "Nuestra situación intelectual” o "El ser sobrenatural: Dios y la deificación en la teología paulina”. Las sucesivas ediciones lo convirtieron bien pronto en un clásico de la filosofía española. También en América Latina fue leído con gran interés este "primum opus zubirianum”, de tal manera que en 1948 se tuvo una edición argentina ${ }^{17}$. En 1949 la Sociedad Peruana de Filosofía designó a Zubiri, “en reconocimiento de los méritos en el ejercicio de la disciplina filosófica”, Miembro de Honor de dicha Sociedad ${ }^{18}$.

Firmaba el diploma Francisco Miró Quesada, quien sentía por la obra de Zubiri un gran aprecio, compartido por otros filósofos de su generación como Cayetano Betancur y Danilo Cruz Vélez en Colombia o Vicente Fatone en Argentina. Fatone publicaba en 1953 una estupenda obra sobre La existencia humana y sus filósofos ${ }^{19}$, en la que presentaba a Zubiri ante el público argentino como uno de los grandes existencialistas, al lado de Heidegger, Jaspers, Marcel, Sartre, etc. Por su parte, el uruguayo Alberto del Campo colaboraba en 1953 en el primer Homenaje a Xavier Zubiri de la revista Alcalá, destacando "la actitud filosófica de

16 GRANEL, Manuel. “Ortega en una anécdota, 1955”. Reproducido en Ortega y su filosofía. Madrid: Ed. Revista de Occidente, 1960, pp. 19-23.

17 ZUBIRI, Xavier. Naturaleza, Historia, Dios. Buenos Aires: Ed. Pollet-El Ateneo, 1948.

18 El diploma reza así: "El Señor Javier Zubiri ha sido designado Miembro de Honor de esta Sociedad en reconocimiento de sus méritos en el ejercicio de la disciplina filosófica. Lima 10 de octubre de 1949. Presidente, firma ilegible; Secretario, Francisco Miró Quesada”.

19 FATONE, Vicente. La existencia humana y sus filósofos. Buenos Aires: Ed. Raizal, 1953. 
Zubiri y su importancia para el pensamiento americano"20.

El tercer cauce de la actualidad de Zubiri fue el magisterio oral a través de los cursos privados, que, a falta de cátedra oficial, un grupo de amigos ponían en marcha en 1945 para que pudiera desplegar su pensamiento ya en trance de maduración. Durante los años cuarenta y cincuenta fueron testigos de excepción de la creatividad del magisterio extrauniversitario de Zubiri cuatro latinoamericanos: el diplomático uruguayo Alberto del Campo, quien dio a conocer dichos cursos, suscitó interesantes polémicas y ha seguido hasta hoy escribiendo importantes ensayos sobre la filosofía de Zubiri; el colombiano Rafael Gutiérrez Girardot, hasta su instalación definitiva en Alemania, donde sería discípulo de Heidegger, profesor en Bonn y brillante ensayista ${ }^{21}$; el mexicano Agustín Basabe y el argentino Enrique Dussel, quienes simultanearon sus estudios de doctorado en la Universidad Complutente de Madrid con la asistencia a dichos cursos. Todos ellos recibieron un fuerte impacto de su magisterio y crearon en América Latina grandes expectativas sobre lo mucho que podría dar de sí Zubiri en un futuro, cuando los cursos orales se transformaran en obra escrita. Dussel, por ejemplo, en sus primeras conferencias de iniciación a la filosofía de la liberación solía alertar a sus oyentes: "hasta qué punto filósofos tan dejados de lado, tales como Zubiri, dicen muchas más cosas de las que uno pueda imaginar y, de paso, son de nuestro mundo hispano. Parecería que en España ya no hay filósofos; los hay, lo que pasa es que a veces no los conocemos”22.

\section{Tercera etapa}

La anterior situación de expectación se prolongó hasta finales de 1962, año en el que por fin vio la luz pública el tratado Sobre la esencia. Quizás por esperado, obtuvo este libro un desproporcionado éxito editorial, hecho que caricaturizó Mingote pintando a la gente apretujada en el metro de Madrid leyendo el libro de Zubiri o haciendo lo propio el Padre Eterno en la soledad del cielo. No obstante tal éxito comercial, el libro de Zubiri produjo una sensación de desencanto no disimulado entre sus viejos amigos de antes de la guerra, y en no pocos lectores de la nueva generación de la posguerra suscitó desconcierto y polémica. Es sintomático al respecto el caso de José Gaos, quien en carta del 3 de octubre de 1963 dirigida a David García Bacca le dice: "Yo no he leído el libro. ¿Por qué? Porque la lectura del índice y hojeo de [Sobre] la esencia me hicieron 'oler' lo que Ud. me confirma para ahorrarme definitivamente la lectura"23. Ambos tuvieron la impresión de que con esta obra se alejaba su viejo amigo Zubiri de la fenomenología y del existencialismo heideggeriano e involucionaba hacia viejas posiciones escolásticas, que para colmo de males servían en esos años de cobertura ideológica catolizante al franquismo. No obstante, en la "Advertencia” preliminar de su Metafísica natural estabilizada, editada en México en 1963,

20 Alberto Del Campo. "La actitud filosófica de Zubiri y su importancia para el pensamiento americano”. En: Homenaje a Xavier Zubiri. Madrid: Ed. Revista Alcalá, 1953, pp. 29-36.

21 GUTIÉRREZ GIRARDOT, Rafael. "Vida de la filosofía. Carta desde Madrid”. En: Ideas y valores 2 (1951) pp. 151-153; "En torno a tres españoles (Zubiri, Aranguren y Rosales)”. En: Guadalupe 1 (1953) pp. 22-29; “A propósito del libro de Zubiri”. En: Cuadernos de filosofía latinoamericana 14 (1983) pp. 9296.

22 DUSSEL, Enrique. Introducción a la filosofía de la liberación. Buenos Aires: Ed. Extemporáneos, 1977; reimpreso con un "Ensayo preliminar" mío en Bogotá, Ed. Nueva América, 1979, pp. 103-104.

23 GAOS, José. Obras completas, vol. XIX, p. 419. 
reconocía García Bacca que, pese a no citar a nadie, debía mucho a todos, “desde Aristóteles a Zubiri”24 . Dentro de esta generación, José Ferrater Mora tuvo una actitud más positiva frente a dicha obra. En las sucesivas ediciones argentinas de su Diccionario de Filosofía ${ }^{25}$, y posteriormente en las españolas, incluyó la palabra “Zubiri”, dando además entrada en múltiples artículos del mismo a conceptos claves de la metafísica zubiriana ${ }^{26}$; contribuyó también a dar a conocer la obra de Zubiri en el mundo angloamericano $^{27}$; y, finalmente, como bien escribe José Luis Abellán, mal podría entenderse su principal obra metafísica El ser y el senti$d o^{28} \sin$ "la presencia de Ortega, de Sartre y, muy evidentemente, la de Zubiri” ${ }^{29}$.

En cuanto a la nueva generación surgida post bellum, hay que aclarar de entrada que el tratado Sobre la esencia fue recibido de muy distinta forma en ambos lados del Océano. En España abundaron más las críticas nega- tivas e incluso despectivas en algunos $\operatorname{casos}^{30}$, que las valoraciones positivas. La objeción más grave al tratado era que “parecía proponer una teoría de la realidad por la que no había pasado Kant ni toda la modernidad ulterior. Se trataba de una metafísica que no iba acompañada de una pareja teoría del conocimiento"31. En América Latina, en cambio, aun reconociendo validez a algunas críticas, se destacaron más los aspectos positivos del libro. Prueba de ello son los comentarios de los argentinos Alberto Caturelli $^{32}$ y María Lucrecia Robaletti ${ }^{33}$; del mexicano Agustín Basabe ${ }^{34}$; de la costarricense María de los Ángeles Giralt ${ }^{35}$, de las portorriqueñas Isabel Trío y Fannie Simonpietri ${ }^{36}$, o del chileno Jorge Eduardo Rivera. En 1964 escribía Rivera un estupendo artículo titulado "La crítica de Zubiri a Heidegger”, en el que entre otras cosas decía que Sobre la esencia "es uno de los libros más extraordinarios que yo haya leído. Todo en él es nuevo. No en el sentido de que

24 GARCÍA BACCA, Juan David. Metafísica natural estabilizada y problemática metafísica espontánea. México: F.C.E., 1963.

25 La $1^{a}$ edición de este clásico Diccionario de filosofía apareció en 1945 en México; en Buenos Aires de la $2^{a}$ a la $5^{a}$, ésta en dos volúmenes y varias reimpresiones; a partir de de la $6^{a}$, en Alianza Editorial de Madrid.

26 Ver los artículos “Constitución”, “Constitutivo”, “Esencia”, “Formalidad”, "Hábito”, “Individuo”, "Inteligencia”, "Real”, "Realidad”, “Substancia”, "Substantividad”, "Substantivo”, “Tal”, "Talidad”, "Transcendente”, “Transcendentales.”

27 FERRATER MORA, José. “The philosophy of Zubiri”. En: European Philosophy Today (1965) pp. 15-29.

28 FERRATER MORA, José. Ser y el sentido. Madrid: Revista de Occidente, 1967.

29 ABELLÁN, José Luis. El exilio filosófico en América: Los transterrados. México: F.C.E., 1998, p. 108.

30 Ejemplo, el Diccionario de filosofía contemporánea (dirigido por M. A. Quintanilla). Salamanca: Sígueme, 1976.

31 GRACIA, Diego. “El Seminario Xavier Zubiri de Madrid”. En: Balance y perspectivas., p. 746.

32 CATURELLI, Alberto. "La metafísica intramundana de Xavier Zubiri”. En: Revista de humanidades (Cordoba, Argentina) 8 (1965) pp. 3-42; y en Humanitas (Monterrey, México) 7(1966) pp. 73-97.

33 ROBALETTI, María Lucrecia. Esencia y realidad: La función trascendental de la esencia en Zubiri. Buenos Aires: López Libreros, 1979.

34 BASABE, Agustín. Tratado de metafísica: teoría de la habencia. México: Ed. Limusa, 1982.

35 GIRALT BERMÚDEZ, María de los Ángeles. El devenir de la esencia en Xavier Zubiri. San José: Universidad de Costa Rica, 1975.

36 TRÍO, Isabel. El tema de la libertad en el pensamiento español contemporáneo. Pamplona: Universidad de Navarra, 1970; y La libertad en Xavier Zubiri. Río Piedras: Universidad de Puerto Rico, 1998. SIMONPIETRI, Fannie. “La antropología filosófica en ‘Sobre la esencia’ de Xavier Zubiri”. En: Diálogos 25 (1973), pp. 103-115. 
Zubiri empiece todo de nuevo, sin tomar en cuenta la tradición, sino que es justamente al revés, porque es un enfrentamiento con toda la tradición filosófica, desde Parménides hasta nuestros días, hecho desde una visión original y, a mi juicio, tremendamente fecunda”37. No obstante tales elogios, Rivera "echaba de menos una aclaración del método intelectual de Zubiri, es decir, concretamente, de su teoría de la inteligencia sentiente”; y, años más tarde, "cuando tuve la suerte de trabajar por casi dos años con Zubiri sobre su propio libro (eran los años 1966-1968) repetidas veces le pedí que escribiera su teoría de la inteligencia”38.

¿Y por qué no hablar de mi propia experiencia? A raíz también de la aparición de Sobre la esencia, comenté el libro en una serie de ensayos publicados en revistas colombianas, posteriormente reunidos en un libro editado en 1965 en España con el título de En torno a Zubiri $^{39}$. Poco después de publicado, aprovechando un viaje que hice a Madrid, me presenté ante Zubiri (a quien todavía no conocía), confesándome “autor de aquel pecado” que ponía en sus manos. Recuerdo que de inmediato me dio un afectuoso abrazo, quizás porque me vió un tanto asustado, y benevolentemente me dijo: "Leí con interés el ejemplar que me envió la editorial; no está mal; pero además todos somos hijos de Adán y nos gusta que nos alaben”. Interpreté esta última frase como un desahogo de alivio frente a tanta crítica negativa como había recibido, que lo sumió en una profunda depresión. Por estos años sesenta, otros latinoamerica- nos, de origen o adopción, como Ignacio Ellacuría (de quien hablaré extensamente), María Lucrecia Robaletti, Jorge Eduardo Rivera, Fernando Danel, y el que esto escribe, tuvimos la suerte de seguir sus cursos y, lo que es más importante, fuimos acogidos dentro del ámbito de la amistad, que Zubiri sabía crear en torno a su persona.

El interés suscitado por el libro de Zubiri, en mi caso y en el de otros muchos latinoamericanos, obedecía a dos problemas fundamentales que teníamos planteados en ese momento: el de nuestra identidad cultural y el de la liberación de nuestros pueblos. Después de dos siglos de colonización y de casi otros dos de convulsa historia independiente, no sabíamos quiénes éramos culturalmente ni cuál era la causa de nuestro subdesarrollo. La generación que surgía en América Latina al término de la segunda guerra mundial se planteó en forma acuciante el primero de estos problemas y ensayó una posible respuesta al mismo desde una filosofía que algunos llamaban "latinoamericana", pero que en todo caso debía ser auténtica, y no "una mala copia”, como decía Leopoldo Zea, de la producida en Europa ${ }^{40}$. Pero más allá de la falta de identidad, nos dolía la pobreza generalizada de nuestros pueblos, dominados por unas seculares estructuras de injusticia. Bajo estas preocupaciones, en 1968 se reunía en Medellín (Colombia) la Conferencia del Episcopado Latinoamericano (CELAM) para poner en marcha la Iglesia de los pobres exigida por las circunstancias e inspirada en el Vaticano II. En este contexto, el peruano

37 Jorge Rivera Cruchaga. "La crítica de Zubiri a Heidegger”. En: Heidegger y Zubiri. Santiago de Chile: Ed. Universitaria, 2001, p. 187.

38 Ibíd., p. 185.

39 MARQUÍNEZ ARGOTE, Germán. En torno a Zubiri. Madrid: Ed. Studium, 1965.

40 ZEA, Leopoldo. La filosofía americana como filosofía sin más. México: Siglo XXI, 1969; SALAZAR BONDY, Augusto. ¿Existe una filosofía en Nuestra América? México: Siglo XXI, 1968; MIRÓ QUESADA, Francisco. Despertar y proyecto del filosofar latinoamericano. México: F.C.E., 1974; MARQUÍNEZ ARGOTE, Germán. ¿Qué es eso de filosofía latinoamericana? Bogotá: El Búho, 1981. 
Gustavo Gutiérrez publicaba en 1971 su Teología de la liberación ${ }^{41}$, obra que convulsionaría el tranquilo discurrir de la teología católica. A la sombra de la nueva teología, irrumpía también con fuerza la filosofía de la liberación latinoamericana, cuyo principal exponente fue, y lo sigue siendo, el argentino Enrique Dussel.

Para la comprensión de ambos problemas nos parecía esclarecedora, a principio de los setenta, la teoría sociológica de la dependencia, como causante del subdesarrollo. En un mundo constituido por uno o varios centros de poder dominante y una periferia dependiente, los países periféricos eran "un-paraotro" y no "para-sí-mismos", siendo por ello subdesarrollados ${ }^{42}$. Junto a esta teoría sociológica, nos parecía relevante la distinción metafísica que hacía Zubiri entre las nociones de "haber", “estar” y "realidad” por una parte, y el concepto del "ser" por otra.

Ya en 1935 trazaba Zubiri un pequeño esbozo de una metafísica no ontológica contraponiendo "haber-ser": "Al conocer, el hombre entiende lo que hay, y lo conoce como siendo. Las cosas se convierten entonces en entes. Pero su ser supone siempre el haber", añadiendo a continuación que "si el idioma griego no hubiera poseído sólo un verbo, el verbo ser, para expresar las dos ideas del ser y del haber, se hubieran simplificado y aclarado notablemente grandes paradojas de su ontología”43. Comentando el anterior texto, escribía en 1953 Alberto del Campo: "Este texto de Zubiri, que se hará clásico en la historia de la filosofía contemporánea, introduce una esencial modificación en el orden de la fundamentación. Ahora sabemos que el ser no es la instancia última a que cabe llegar, porque el ser está ya fundado y se funda en el haber, en lo que hay, en la realidad... Zubiri es el primer filósofo que ha logrado ir más allá del ser”44. Poco después Julián Marías replicaba "al escritor uruguayo" (sin citarlo nominalmente) atribuyendo la autoría de dicha distinción a Ortega y no a Zubiri ${ }^{45}$. Sea el que fuere su origen, lo importante es la gran aceptación que tuvo en el pensamiento hispanoamericano esta distinción. Además de Ortega y Zubiri, la hizo suya Manuel García Morente en sus famosas Lecciones preliminares de filosofía, dadas en el año 1937 en la Universidad argentina de Tucumán y publi-

${ }^{41}$ GUTIÉRREZ, Gustavo. Teología de la liberación: perspectivas. Lima: CEP, 1971.

42 CARDOSO, F. H. y FALETTO, E. Dependencia y subdesarrollo en América Latina. 24a. ed. México: Siglo XXI, 1978; FURTADO, C. El desarrollo económico: un mito. México: Siglo XXI, 1976.

43 ZUBIRI, Xavier. Naturaleza, Historia, Dios, p. 436.

44 DEL CAMPO, Alberto. "Haber y ser en la filosofía de Zubiri”. En: Revista (Barcelona), septiembre (1954), pp. 23-29. "Toda la filosofía contemporánea se lanzó precipitadamente por el camino del ser... Frente a este criterio compartido por los mejores pensadores de nuestro siglo, Zubiri sospechó hace años que se estaba desconociendo y pasando por alto una instancia previa y aún más radical que la del sentido del ser“.

45 MARÍAS, Julián. "Realidad y ser en la filosofía española”. En: Insula 117 (1955), pp. 1 y 9; reimpreso en Obras. Madrid: Revista de Occidente, 1960, vol. V, pp. 497-507. En dicho ensayo Marías afirma que "la insatisfacción que la filosofía española de nuestro tiempo ha sentido frente a la noción del ser, la ha llevado a plantear - por lo menos a empezar a plantear - el problema filosófico de la realidad como tal o del haber, y por tanto a buscar una metafísica que esté más allá de la ontología y que pueda dar razón de ella”; y analizando la obra de Ortega, encuentra dicha distinción en los cursos que dio a partir de 1929, hoy ya publicados. En Unas lecciones de metafísica, Lección III, se pregunta Ortega: “¿Qué es lo que hay? No ¿qué hay? Esto lo tengo ya, porque vivir es estar en las cosas, habérselas con ellas; y por tanto haber éstas ante mí: las tengo desde luego, las hay desde luego y, por eso estoy perdido entre ellas. Lo que se pregunta no es, pues, lo que hay, sino qué es lo que hay, cual es el ser de lo que hay". 
cadas en Buenos Aires en $1938^{46}$. Por su parte, Ferrater Mora en Ser y sentido escribía: "En alguna medida tuvo razón Ortega cuando repetidamente sostuvo que el ser es una invención humana. En todo caso, la noción del ser es el resultado de una objetivación del hombre. La objetivación tiene como fundamento las realidades con las que yo me encuentro en el mundo. El mundo es el conjunto de las cosas que hay" ${ }^{47}$. Posteriormente recurrieron a la misma el argentino Agustín de la Riga ${ }^{48}$ y el mexicano Agustín Basabe, quien en 1974 publicaba un grueso Tratado de metafísica, pretendiendo desarrollar una "nueva metafísica” como "teoría de la habencia”, que superara el “carácter cósico del realismo zubiriano, conservando todos sus sólidos y penetrantes aciertos”49.

En los años setenta, Enrique Dussel, siguiendo a Zubiri, hacía suya la distinción entre ser y realidad y, consiguientemente, entre ontología y metafísica: “Contra la ontología clásica del centro se levanta una filosofía de la liberación de la periferia, de los oprimidos, de la sombra que la luz del ser no ha podido iluminar. La filosofía de la liberación pretende así formular una metafísica — que no es ontología - exigida por la praxis revolucionaria" ${ }^{50}$. Otro tanto escribía Osvaldo Ardiles en 1973: “Confundiendo las nociones de realidad y de ser el pensar de la dominación obtuvo un reaseguro ontológico de la permanencia de lo existente. Pero la necesaria labor de distinción... nos obliga a distinguir con Zubiri, al ser como un momento de lo real" ${ }^{51}$.

Yo mismo, en mi Metafísica desde Latinoamérica, escribía en 1977: "Se nos puede negar el ser, se nos puede decir que no somos nadie en el mundo, pero nadie podrá quitarnos lo que 'hay' en nuestro mundo, si nosotros sabemos defender estos haberes propios. Podemos seguir siendo, a los ojos de la ontología, instalada mundialmente, irrelevantes. Pero metafísicamente, es decir, realmente, nuestra realidad es rica. Se trata de

46 GARCÍA MORENTE, José. Lecciones preliminares de filosofía. Buenos Aires: Ed. Losada, 1973. Allí escribe: "En nuestras vidas 'hay' cosas reales, objetos ideales y valores... ¿Qué significa eso que yo expreso con la palabra 'hay'?... Ese 'haber' no significa otra cosa que la totalidad de la existencia”, p. 386.

47 FERRATER MORA, José. Ser y el sentido. Madrid: Revista de Occidente, 1967. No obstante, en abierta crítica a Zubiri añade Ferrater: "Considerar las realidades desde el punto de vista de lo que hay ofrece ventajas que las nociones de 'realidad', 'ser real' y otras similares dejan escapar fácilmente. Hablar de la realidad o del ser real equivale las más de las veces a cosificar lo que hay: el ser real es visto entonces como res, como cosa. En cambio, la noción 'de lo que hay’ no está necesariamente adscrita a la idea de cosa; característico de lo que hay es el haberlo de diversos modos y maneras, entre las cuales figuran el ser cosa y el ser entidad, pero sin que éstos agoten el repertorio de lo que hay”.

48 DE LA RIGA, Agustin. “América fuera del centro, del privilegio y de la culpa”. En: Hacia una filosofía de la liberación latinoamericana. Buenos Aires: Ed. Bonum, 1974, p. 210. Allí escribe: "El haber es modo liberador de señalar la realidad... La filosofía del haber es revolucionariamente liberadora porque su fundamentación no pasa por el Centro... Su justicia es la de la simplicidad: allí donde hay, es eso que hay. Eso que hay en su propia dignidad. En su propia verdad”.

49 BASABE, Agustín. Tratado de metafísica: teoría de la habencia. México: Ed. Limusa, 1974.

50 DUSSEL, Enrique. Método para una filosofía de la liberación. Salamanca: Ed. Sígueme, 1974, p. 128. En la misma escribe que "es necesario hacerse cargo de la metafísica de este gran pensador compentopáneo", con quien ha seguido dialogando en Ética de la liberación en la edad de la globalización y de la exclusión (Madrid: Trotta, 1998); ver así mismo: “La teoría de la verdad de Zubiri y sus necesarias mediaciones”. En: Debate y perspectiva..., pp. 585-598. Ver también MARQUÍNEZ ARGOTE, Germán. “Zubiri visto desde Latinoamérica: Aportes a la filosofía de la liberación”. En: ECA (Salvador) 346 (1977), pp. 475-484. 1974.

51 ARDILES, Osvaldo. "Ethos, cultura y civilización”. En: Cultura popular y filosofía de la liberación. Buenos Aires: Ed. Fernando García, 1975, p. 932. 
quitarnos el complejo de ser a cualquier costo. Solamente desde nuestra realidad asumida podremos, en acto segundo, ser o representar algo. Lo ha entendido así la joven novela latinoamericana. Lo está comprendiendo la filosofía" 52 .

En 1975 Rodolfo Kuch publicaba América profund $a^{53}$, poniendo de moda una nueva corriente, conocida como "filosofía inculturada", que utilizaba la distinción "estar-ser" en el análisis de la cultura americana. En dicho libro denunciaba Kuch la prepotencia de las culturas del ser y su destructora competencia mundial frente a las culturas del estar o del arraigo telúrico propio de los pueblos americanos. Nuestra cultura se expresa en el colectivo y solidario "nosotros estamos", un estar que no renuncia a ser, sino que lo fundamenta y le da sentido. De aquí que, para connotar que el ser es una actualidad segunda radicada en el estar, se recurriera a la expresión "estar siendo”, con el ser en gerundio. Porque sólo implantados sin complejos en nuestra propia realidad, será posible ser en forma auténtica y liberada. Los planteamientos de Rodolfo Kuch fueron completados y profundizados por Carlos Cullen ${ }^{54}$ y Juan Carlos Scannone ${ }^{55}$. Me consta que Scannone conocía la distinción entre estar y ser tal como aparece en Sobre la esencia y, posteriormente, en Inteligencia y razón, donde Zubiri concluye afirmando que "el gran problema humano [es] saber estar en la realidad" ${ }^{\text {, }}$, frase que resume el espíritu de la filosofía inculturada.

Pero, sin quitar nada a nadie, hay que reconocer que a partir de los años sesenta Zubiri se hizo presente en América Latina principalmente por la persona y obra de su alter ego, Ignacio Ellacuría. En 1965 presentó su tesis doctoral en la Universidad Complutense de Madrid con el título de "La principialidad de la esencia en Xavier Zubiri”, confeccionando además unos minuciosos Índices de la obra de Zubiri ${ }^{57}$. Estos años constituyeron el punto de partida de una fecunda relación de amistad y colaboración entre ambos vascos universales. Permítanme recordar aquí cómo conocí a Ignacio en una tarde de otoño de 1968 en el Colegio Mayor Miguel Antonio Caro de la Ciudad Universitaria de Madrid. Estaba alojado en una modesta habitación en la que trabajaba sobre los cursos inéditos de Zubiri, cuyos textos había puesto en sus manos, tratando de armar con ellos un tratado de antropología, el que sería publicado en 1986 (tres años después de muerto Zubiri y tres antes de la trágica desaparición de Ignacio) con el título de Sobre el hombre. Recuerdo que en este primer encuentro hablamos entre otras cosas de la conveniencia de recoger en un volumen algunos de los textos antropológicos de Zubiri dispersos en revistas, idea que llevé a cabo años después, con el beneplácito de Zubiri, en Colombia.

52 MARQUÍNEZ ARGOTE, Germán. Metafísica desde Latinoamérica. "Tercera jornada: ¿ontología y/o metafísica?”. Bogotá: USTA, 1977. Ver también: “Metafísica”, “Ontología”. En: Diccionario del pensamiento contemporáneo. M. Moreno Villa (Ed.). Madrid: San Pablo, 1977.

53 KUCH, Rodolfo. América profunda. Buenos Aires: Bonum, 1975.

54 CULLEN, Carlos. Fenomenología de la crisis moral: sabiduría de la experiencia de los pueblos. Buenos Aires: Castañeda, 1978

55 SCANNONE, Juan Carlos. Sabiduría popular, símbolo y filosofía. Buenos Aires: Guadalupe, 1984; Nuevo punto de partida de la filosofía latinoamericana. Buenos Aires: Guadalupe, 1990.

56 IRA, 351-352. Ver: SCANNONE, Juan Carlos. "Liberación: un aporte original del cristianismo latinoamericano”. En: Enciclopedia iberoamericana de filosofía: Religión. Madrid: Trotta, pp. 93-95.

57 Ver "Conclusiones" de la tesis doctoral de I. Ellacuria, en: MORA GALIANA, José. Homenaje a Ignacio Ellacuría. Huelva: Diputación, 2001, pp. 71-104; Índices de Sobre la esencia. Madrid: Sociedad de Estudios y Publicaciones, 1965. 
Ya en estos años eran patentes las dos grandes pasiones de Ignacio: la realidad de América Latina y la filosofía de Xavier Zubiri; pero todavía daba la impresión de que andaban un poco sueltas o no suficientemente articuladas la una con la otra en su pensamiento y en la praxis exigida por la realidad americana. Cuando en años posteriores, en alguno de nuestros ires y venires entre los dos mundos, coincidíamos en Madrid, era patente el cambio que se iba operando en este jesuita, digno de la mejor Compañía. Obligado a asumir o, como él solía decir, a "cargar con” la dura realidad vivida por el pueblo salvadoreño, hizo suya la teología de la liberación, de la que llegaría a ser uno de los principales exponentes. Pero al mismo tiempo fue descubriendo en la metafísica zubiriana un inagotable filón de posibilidades para "hacerse cargo" razonablemente de la realidad que le tocaba vivir y para "encargarse” de transformarla, como intelectual responsable que era, con los medios de que disponía: su despierta inteligencia, su clara voz y principalmente su pluma, que no dejó de fluir un solo día, enfrentando los graves problemas de la realidad salvadoreña en forma crítica y arriesgada. Tan arriesgada, que una nota editorial publicada en ECA en 1976 con el título “A sus órdenes mi Capital” valió el primer destierro, que pasó en Madrid junto a Zubiri. Cuando en 1977 le envié desde Colombia un ejemplar de mi Metafísica desde Latinoamérica, me escribió una carta en la que entre otras cosas me decía:
Yo, por mi parte, entre otros trabajos menores, estoy trabajando en una filosofía de la historia que tengo muy avanzada y que es posible esté preparada para la imprenta en diciembre de este año, sobre todo si sigue mi exilio forzado. Será un libro grande en que también pongo el pensamiento de Zubiri al servicio del filosofar latinoamericano.

Libro grande éste no sólo por el número de páginas (más de 500 y la obra quedó incompleta), sino porque en esta obra pudo por fin Ignacio articular el pensamiento de Zubiri con la realidad latinoamericana Filosofía de la realidad histórica ${ }^{59}$, que así se titulaba esta obra póstuma publicada en 1990, se insertaba en una de las corrientes más vivas del pensamiento latinoamericano: el historicismo. Sus representantes, José Gaos, Leopoldo Zea, Arturo Ardao, Andrés Arturo Roig, entre otros ${ }^{60}$, hacían de la historia el lugar común de todo sentido y, en consecuencia, la única realidad que nos podría revelar el ser de nuestros pueblos. No se trataba de una reviviscencia del viejo historicismo relativizante y escéptico, que todo lo disuelve en puro devenir, sino de un nuevo historicismo raizal que pretendía dar razón de lo que somos, mirándonos en el espejo de lo que fuimos. Nada es comprensible fuera del contexto histórico.

Para escribir su Filosofía de la realidad histórica tuvo presente Ignacio Estructura di-

58 Ignacio Ellacuría. “A sus órdenes mi capital”. ECA, 337 (1976) pp. 637-643; recogido en Escrítos políticos I. San Salvador: Ed. UCA, 1991, pp. 649-656.

59 ELLACURÍA, Ignacio. Filosofía de la realidad histórica. San Salvador: UCA, 1990; Madrid: Trotta Fundación Xaxier Zubiri, 1991.

60 ZEA, Leopoldo. Filosofía de la historia americana. México: F.C.E., 1978; ARDAO, Arturo. "El historicismo y la filosofía latinoamericana”. En: Filosofía de lengua española: ensayos. Barcelona-Montevideo: Alfa, 1963; ROIG, Arturo Andrés. "Las ontologías contemporáneas y el problema de nuestra historicidad”. En: Teoría y critica del pensamiento latinoamericano. México: F.C.E., 1981; CERUTTI GULDBERG, Horacio. Filosofar desde nuestra América. México: Purrúa, 2000. 
námica de la realidad, curso dado por Zubiri en 1968, al que tuve la suerte de asistir. En él respondía Zubiri a quienes le acusaban de presentar una visión metafisica quiescente de la realidad en Sobre la esencia. En el nuevo libro sostenía que la realidad material es de suyo dinámica, es decir, produce desde sí misma "hechos" en un devenir de pontencialidades que constituye la evolución. Pero, la realidad humana es, además, capaz de producir "sucesos o eventos", previa creación y apropiación de posibilidades. A esta invención optativa y cumplimiento de posibilidades era a lo que "de manera muy monótona a lo largo de los años, he llamado historia, historicidad" ${ }^{61}$. En contra de Teilhard de Chardin, quien, fundiendo y confundiendo evolución e historia, describía "en términos grandiosos la marcha de la evolución”'22, sotenía Zubiri que "el proceso histórico no es prolongación del proceso evolutivo" y que, por tanto, el devenir de potencialidades y el devenir de posibilidades son dos cosas distintas. En conclusión, la historia es para Zubiri una dimensión formal y exclusiva del ser del hombre.

Ellacuría, en cambio, empezaba su libro afirmando rotundamente que el objeto de la filosofía es "la realidad histórica", que globalmente entendida no es otra cosa que "el todo de lo real dinámicamente considerado”. En consecuencia, entendía la historia, un poco teilhardianamente, como un carácter de la "omnitudo realitatis" o realidad total, estructuralmente evolutivo-histórica. En esta forma podía sostener la materialidad de la historia, recurriendo al materialismo metodológico de Marx, para quien las condiciones materiales de producción y las rela- ciones sociales que en aquellas se generan, constituyen la infraestructura o base material de la historia; pero inspirándose también en el "materismo" antropológico zubiriano, que definía al hombre como animal de realidades, corporeidad anímica, inteligencia sentiente, persona corpórea o cuerpo personal, etc. Las posibilidades no se las saca el hombre de la manga, sino de las condiciones y potencialidades de la materia, de modo que ambos devenires terminan coimplicándose estructuralmente el uno con el otro, tanto a nivel individual como social, de modo que evolución e historia no conforman una unión de dos cosas acopladas, sino una estricta unidad de dos dinamismos actuantes dentro de la estructura cósmica total. De este modo, sin caer en el monismo materialista de Engels, Ignacio se alejaba al mismo tiempo de las diversas concepciones idealistas de la historia, lo cual le permitía comprender los problemas concretos de las personas de carne y hueso con sus necesidades materiales, sin cuya satisfacción mal podrían acceder a los niveles de realización más altos o espirituales. A mi juicio, materializando la realidad histórica, desde Zubiri y con Zubiri, Ignacio Ellacuría va más allá de Zubiri. Porque, si se admite con Zubiri que la sustantividad humana no es una unión de cuerpo y alma, sino una unidad psicosomática, yo me pregunto: ¿No habrá que afirmar análogamente que evolución e historia más que unión de dos cosas bien acopladas, conforman una unidad "evolutivo-histórica" en la "sustantividad total" del Cosmos, de la cual forma parte la "sustantividad humana"?

En la última parte de su obra, que no le dieron tiempo de escribir, pensaba mostrar Ig-

${ }_{61}$ ZUBIRI, Xavier. El hombre y la verdad. Madrid: Alianza, 1999, p. 100. Ver mi trabajo, "El problema de la historicidad del ser del hombre”. En: Balance y perspectivas..., pp. 209-215.

62 ZUBIRI, Xavier. "La dimensión histórica del ser humano". En: Siete ensayos de antropología filosófica. Bogotá: USTA, 1982, p. 129; ver también: Estructura dinámica de la realidad. Madrid: Alianza, 1989, p. 179. 
nacio la intencionalidad liberadora de su filosofía de la realidad histórica: "Si en América Latina se hace auténtica filosofía en su nivel formal, en relación con la praxis histórica de liberación y desde los oprimidos, que constituyen la sustancia universal, es posible que se llegue a constituir una filosofía latinoamericana, como se ha constituído una teología latinoamericana y una novelística latinoamericana que, por ser tales, son además universales”63.

\section{Cuarta etapa}

La cuarta etapa corresponde a la última generación, la que se introduce en la filosofía de Zubiri en los años ochenta leyendo Inteligencia sentiente, obra canónica, desde la cual, según se dice, hay que releer y reinterpretar todo lo anteriormente pensado y escrito por Zubiri. En este contexto, se deben situar los trabajos que se están llevando a cabo en el más reciente ayer y hoy mismo. Imposible reseñar aquí toda la producción en torno a Zubiri en los diversos países América Latina, que por otra parte se puede consultar en www.zubiri.net. Por esta razón, me voy a referir solamente a tres de los centros de investigación más activos y organizados: El Salvador, Colombia y Chile.

Con toda justicia, el pensamiento ellacuriano está recibiendo especial atención en la Universidad Centroamericana de El Salvador, donde Ignacio enseñó y murió, donde se encuentran los fondos de su archivo personal ${ }^{64}$ y donde está en curso de publicación lo que serán, en un próximo futuro, sus Obras completas, que suman ya un total de once volúmenes entre escritos filosóficos, políticos, teológicos y universitarios ${ }^{65}$. Al mismo tiempo, se están publicando numerosos estudios sobre su pensamiento ${ }^{66}$, entre los cuales merece mención especial el ejemplar libro de Héctor Samour recientemente editado con el título de Voluntad de liberación: la filosofía de Ignacio Ellacuría ${ }^{67}$. En él contextualiza el pensamiento ellacuriano, esclarece su evolución y establece las posibles cotas de originalidad a las que pudo llegar Ignacio a partir del pensamiento de su maestro y amigo Xavier Zubiri. Por otra parte, aunque editadas en España, hay dos obras de creación filosófica que fueron concebidas y escritas en San Salvador, donde en los años

63 ELLACURÍA, Ignacio. "Función liberadora de la filosofía”. En: ECA, 435-436, 1985, p. 64.

64 REYES RAMÍREZ, Rocío. El archivo de Ignacio Ellacuría. Sevilla: Universidad Internacional de Andalucía, 2002.

65 Lo que serán las Obras completas de I. Ellacuría suman ya diez volúmenes: 4 vols. de Escritos filosóficos; 3 vols. de Escritos políticos; 3 vols. de Escritos teológicos; y 1 vol. de Escritos universitarios.

66 El interés creciente sobre la obra de I. Ellacuría se manifiesta en múltiples trabajos, entre los que recomendamos: DOMÍNGUEZ, Manuel. "Ignacio Ellacuría, filósofo de la realidad latinoamericana”. En: Universitas philosophica, 13. Bogotá, 1989, pp. 69-88; GONZÁLEZ, Antonio. “Aproximación al pensamiento de Ignacio Ellacuría”. En: ECA, San Salvador, noviembre-diciembre, 1990; FLORES, Víctor. El lugar que da verdad: la filosofía de la realidad histórica de Ignacio Ellacuría. México: Universidad Iberoamericana/Porrúa, 1997. SOBRINO, J. y ALVARADO, R. (eds.). Ignacio Ellacuría, aquella libertad esclarecida. Santander: Sal Terrae, 1999. SAMOUR, Hector. "Introducción a la filosofía de la liberación de Ignacio Ellacuría”. En: El compromiso político de la filosofía en América Latina. Bogotá: El Búho, 1994.

67 SAMOUR, Héctor. Voluntad de liberación: la filosofía de Ignacio Ellacuría. Granada: Comares, 2003. 
noventa desempeñaron actividades académicas sus autores: Antonio González y Jordi Corominas ${ }^{68}$.

La primera es Estructuras de la praxis: ensayo de filosofía primera ${ }^{69}$. En ella, partiendo de Husserl, Heidegger y Zubiri, Antonio González elabora una filosofía primera que tiene por objeto el estudio de todos los actos humanos, sean perceptivos, imaginativos, intelectivos, afectivos o volitivos, etc., en su rica variedad y sin privilegio alguno. En su claro y riguroso estudio Antonio González se atiene a los postulados del método fenomenológico, poniendo entre paréntesis aquellas instancias que se suponen bien por debajo de los actos o bien allende los mismos. Por ejemplo, cuando "(yo) dudo (de algo)", el "yo" que duda y ese "algo" sobre lo que dudo son instancias que hay que poner entre paréntesis, porque no tienen la inmediatez del acto mismo de dudar. El método analítico obliga a atenerse a los actos en su pura ejecución, describiéndolos tal como se presentan en sus distintas configuraciones, como son las acciones, las actuaciones y las actividades humanas. No podemos resumir aquí los complejos análisis de esta valiosa obra. Pero hay un hecho fundamental que Antonio Gonzalez destaca y que con toda justicia atribuye a Zubiri: es el carácter de "alteridad radical" con el que las cosas se actualizan o están presentes en nuestros ac- tos. No obstante, se niega a llamar "realidad" a dicho "carácter de alteridad", porque el término "realidad" presenta las mismas dificultades que el término "subjetividad"; ambos apuntan "a una trascendencia ilegítimamente introducida en la inmanencia de nuestros actos" ${ }^{\prime 0}$. En este punto Antonio González se aparta evidentemente de Zubiri. Está en su derecho. Pero la pregunta es si se trata de una simple cuestión terminológica (quaestio de terminis) o de un planteamiento que afecta al fondo mismo del problema (quaestio de rebus) ${ }^{71}$. Y el problema está en cómo es posible pasar de algo inmanente, como es el carácter de "alteridad radical", a algo trascendente, como es la "realidad profunda" o mundanal, si no hay algo común a ambos momentos, que en el caso de Zubiri es la "formalidad de realidad”. Es una duda que espero, en mi ignorancia, que los especialistas en noología me sabrán resolver.

Un proyecto similar y complementario al de Antonio González es el realizado por Jordi Corominas en su bien estructurada Ética primera: aportación de Zubiri al debate ético contemporáneo ${ }^{72}$. Asumiendo la distinción entre filosofía primera y metafísica, análisis y teoría, descripción de hechos y explicación de los mismos, pretende elaborar una ética primera cuyo objeto es la mera descripción de los actos humanos en tanto que morales, poniendo entre paréntesis cualquier explica-

68 Antonio González, hoy Secretario General de la Fundación Xavier Zubiri, fue director del Departamento de Filosofía de la UCA durante 1995-1998. Jordi Corominas fue director del programa de Doctorado en Filosofía Latinoamericana de la UCA desde su apertura hasta mayo del 2002.

69 GONZÁLEZ, Antonio. Estructuras de la praxis: ensayo de filosofía primera. Madrid: Trotta, 1997. La Introducción está fechada "San Salvador, agosto de 1996".

70 Ibíd., pp. 38-39.

71 Antes de Escoto nadie había empleado el neologismo latino "realitas", y todavía en el siglo XVIII la palabra "realidad" era considerada bárbara. Hoy forma parte de nuestro lenguaje cotidiano y se ha convertido en término central en la noología y en la metafísica zubiriana. Ver: “Génesis de la palabra realidad”. En: MARQUÍNEZ ARGOTE, Germán. Realidad y posibilidad: fundamentos de ética y educación. Bogotá: Magisterio, 1975.

72 COROMINAS, Jordi. Etica primera: aportación de Zubiri al debate ético contemporáneo. Barcelona: Herder, 1999. 
ción de los mismos que trascienda el ámbito noológico. Más allá de esta ética primera descriptiva, de carácter fáctico y por ello universal, admite Corominas la necesidad de otras éticas que den razón de los diversos proyectos morales con los que puede el hombre orientar su vida. Pero tales éticas racionales, aunque legítimas y necesarias, no tienen el mismo grado de positividad y, por consiguiente, de universalidad que la ética primera. Corominas considera que esta ética primera, de raigambre zubiriana, constituye "una tarea siempre inacabada que quizás brinde sus mejores frutos en el siglo que acaba de empezar"73.

El segundo núcleo importante, donde se ha cultivado en forma sistemática y continua la filosofía de Zubiri, es Colombia. Un grupo de profesores universitarios crearon en 1980 el Seminario Xavier Zubiri que, con altos y bajos, ha seguido funcionando hasta nuestros días. También desde 1980 se vienen celebrando cada dos años en la Universidad Santo Tomás de Bogotá los afamados Congresos Internacionales de Filosofía Latinoamericana, por los cuales han desfilado las grandes figuras de la filosofía en nuestro continente. En los nueve congresos celebrados hasta hoy ha estado presente la filosofía de Zubiri en algunas ponencias y en una mesa especializada sobre estudios zubirianos. A algunos de estos congresos asistieron en su día Diego Gracia, Antonio Pintor, Adela Cortina, etc. Un hecho importante es que en
1982 vio la luz en Colombia, con el beneplácito de Zubiri, Siete ensayos de antropología filosófica ${ }^{74}$, libro en el que se recogían siete ensayos dispersos en varias revistas españolas, todos ellos referentes al hombre en su origen, constitución y dimensiones. Este mismo año de 1982 apareció en Colombia mi Filosofía de la religión ${ }^{75}$, que dediqué: "A Xavier Zubiri en la dorada cima de sus LXXXIII años de juventud”. En esta ocasión, recibí una carta de Zubiri, fechada en Madrid, 16-7-82, en la que entre otras cosas me decía: "Mi querido Germán: En punto a pecados mortales de tardanza, ahí nos vamos los dos. Y ambos quedamos absueltos por nuestra vieja amistad. Acabo de escribir a nuestro común amigo Luis José González Álvarez agradeciéndole su amabilidad. Y pidiéndole, en su nombre, algunos ejemplares más [de Siete ensayos de antropología filosófica], testimonio vivo de lo mucho que me ha satisfecho moral y materialmente la publicación. Pero sobre todo quiero manifestarle cuánto me conmovió la dedicatoria impresa de su Filosofía de la religión”.

Entre los muchos estudios publicados en Colombia $^{76}$, me voy a referir brevemente a dos cuyo objeto es la educación. Rafael Antolínez se ha preguntado "¿Por qué es importante educar los sentidos?”. La respuesta es que educando los sentidos lo que estamos haciendo es educar la inteligencia en su raíz misma sentiente ${ }^{77}$. Cada sentido constituye un analizador distinto del sentir in-

73 COROMINAS, Jordi. “La ética de Zubiri”. En: Balance y perspectivas..., p. 245.

74 ZUBIRI, Xavier. Siete ensayos de antropología filosófica. Edición e Introducción de Germán Marquínez Argote. Bogotá: USTA, 1982.

75 MARQUÍNEZ ARGOTE, Germán. Filosofía de la religión. Bogotá: USTA, 1982.

76 Han escrito sobre la filosofía de Xavier Zubiri: Manuel Domínguez, Luis Enrique Ruiz, Fideligno Niño, Rafael Antolínez, Gabriel Suárez, y un servidor; sus trabajos son consultables en la Bibliografía de Xavier Zubiri, en www.zubiri.net, con excepción quizás del libro de Gabriel Suárez Socialidad de la persona humana (Bogotá: Universidad Javeriana, 2001).

77 ANTOLÍNEZ, Rafael. “¿Por qué es importante educar a los sentidos: una respuesta desde el pensamiento de Zubiri”. En: Cuadernos de filosofía latinoamericana 38-39, 1989, pp. 75-84. Está próxima la publicación de la tesis dotoral del mismo autor sobre este tema. 
telectivo, mediante el cual se actualiza la realidad bajo modalidades diversas e insustituibles. Por su parte, Fideligno Niño en su Antropología pedagógica ${ }^{78}$ y en trabajos posteriores, destaca tres de las que, a su modo de ver, "son rotundas contribuciones de Zubiri a una educación de y hacia valores: su concepción de la persona, dimensionalmente individual, social e histórica, abierta a una permanente e inclausurable tarea de realización. Su idea de la apropiacion del universo del sentido en cuanto posibilidad de buena vida. Su hallazgo de la capacitación como empoderamiento individual y social, objeto principal de solicitud pedagógica para que nos enrrumbe hacia inéditos y cada vez más elevados estadios de humanización”79.

El tercer núcleo de estudiosos de Zubiri es el chileno. También en Chile funciona un Seminario Xavier Zubiri, fundado por Jorge
Eduardo Ribera y secundado por Ricardo Espinoza en la Universidad de Valparaíso. Hay que reconocer el singular esfuerzo que el grupo chileno está haciendo por aclarar el íntimo entreveramiento del pensamiento zubiriano con el heideggeriano. Ejemplar en este punto es el magisterio de Jorge Eduardo Ribera, quien recientemente nos ha regalado una ejemplar traducción de Ser y tiem$p o^{80} \mathrm{y}$ ha puesto en evidencia las profundas relaciones existentes entre sus dos grandes maestros en su últina obra: Heidegger y Zubiri ${ }^{81}$.

Después de este rápido recorrido por las cuatro etapas de la recepción e influencia de la filosofía de Zubiri en América Latina, es posible albergar la esperanza de que algún día nuestro filósofo llegue a ser un clásico de la filosofía.

Alcalá de Henares, 2 de julio de 2004.

78 NIÑO, Fideligno. Antropología pedagógica: intelección, voluntad y afectividad. Bogotá: Magisterio, 1998.

79 NIÑO, Fideligno. "Educación en valores: una aproximación desde Zubiri”. En: Balance y perspectivas..., p. 650.

80 HEIDEGGER, Martin. Ser y tiempo (traducción, Prólogo y notas de Jorge Eduardo Ribera). Santiago de Chile: Ed. Universitaria, 1998; 2a. ed. Madrid: Trotta, 2003.

81 RIVERA CRUCHAGA, Jorge. Heidegger y Zubiri. Santiago de Chile: Ed. Universitaria, 2001. Recientemente, Ricardo Espinoza Lolas, discípulo de Rivera, ha defendido en la Universidad Autónoma de Madrid su tesis doctoral sobre la relación Zubiri-Heidegger; ver una parte de la misma: "Sein und Zeit como el horizonte problemático desde donde se bosquejó el pensamiento de Zubiri”. En: Balance y perspectivas..., pp. 437-481. 